\title{
COMPARATIVE STUDY OF THE ACTION OF THIOTEPA AND TRIAMCINOLONE ON CORNEAL VASCULARIZATION IN RABBITS*
}

\author{
BY \\ G. LAVERGNE $\dagger$ AND I. A. COLMANT \\ From the Department of Ophthalmology, University of Liege, Belgium (Director: Prof. R. Weekers)
}

CORNEAL vascularization is always a pathological phenomenon, which though sometimes necessary for the cure of an inflammatory process, is often incompatible with good visual function. It is always a serious complication in cases in which corneal transplantation is contemplated.

Treatment may be aimed at the prevention of vascularization or to its removal when once established.

Surgical Methods.-The following were recommended by Offret and Chauvet (1950), Offret (1952), Paufique and Rougier (1957), and Guillaumat, Paufique, de SaintMartin, Schiff-Wertheimer, and Sourdille (1961):

Removal of the pannus, as in trachoma;

Surgical or diathermic peritomy;

Heat cauterization or, better still, diathermo-coagulation of the large limbal vessels from which the corneal vessels arise;

Keratectomy;

Corneal transplantation.

Ionizing Rays.-The following have been suggested:

Radiotherapy in an anti-inflammatory dosage (Offret and Chauvet, 1950; Offret, 1952; Paufique and Rougier, 1957; Alberth, 1961a);

Collyrium containing radioactive iodine (Angius, 1954)

Beta-rays (Illiff, 1946, 1947; Offret, 1952; Hallermann, 1961; Paufique and Rougier, 1957; Alberth, 1961a).

Drugs.-These may prevent or reduce invasion of the cornea.

Corticosteroids are among those most frequently mentioned as effective in this respect, but more recently Langham (1960) and Meacham (1962) have succeeded in inhibiting corneal vascularization by the local application of the antimitotic Thiotepa.

The object of this paper is to report our findings concerning the inhibitory action of a corticosteroid (Triamcinolone) and an antimitotic (Thiotepa) on corneal vascularization in rabbits. Triamcinolone (9-fluoro-16-hydroxyprednisolone) was used in the acetonide form in a $\mathbf{0 . 1}$ per cent. ointment (Kenacort A, Labaz $\ddagger$ ).

\footnotetext{
* Received for publication November 6, 1963.

+ Associé au Fonds National de la Recherche Scientifique.

¥ We are indebted to the firms of Labaz and Cyanamid, who kindly supplied us with the samples of Kenacort A and Thiotepa required for our experiments.
} 
Thiotepa ( $\mathrm{N}, \mathrm{N}^{\prime}, \mathrm{N}^{\prime \prime}$-triethylene-thiophosphoramide) is a sulphurated alkalinizing agent which is chemically and pharmacologically very similar to other anticancerous agents such as the nitrogen mustards and triethylene-melamine. It has pronounced antimitotic characteristics. The liberated ethylene-imine radicals block cellular division. In general, the substance is dangerous; because of its leucocytopenic and cytotoxic action, it depresses haematopoiesis and causes emaciation. We administered this drug in an oily collyrium according to the formula recommended by Langham (1960). When the drug is given in this form, its absorption is minimal and no systemic changes occur.

\section{Methods}

To produce vascularization the cornea was cauterized in 75 rabbits by touching it with a tampon soaked in a 20 per cent. caustic soda solution. This effected immediate and homogeneous opacification of the cornea, and a dense vascularization occurred within a week. When left untreated, it reached the centre of the cornea in 4 to 8 weeks (Fig. 1).*

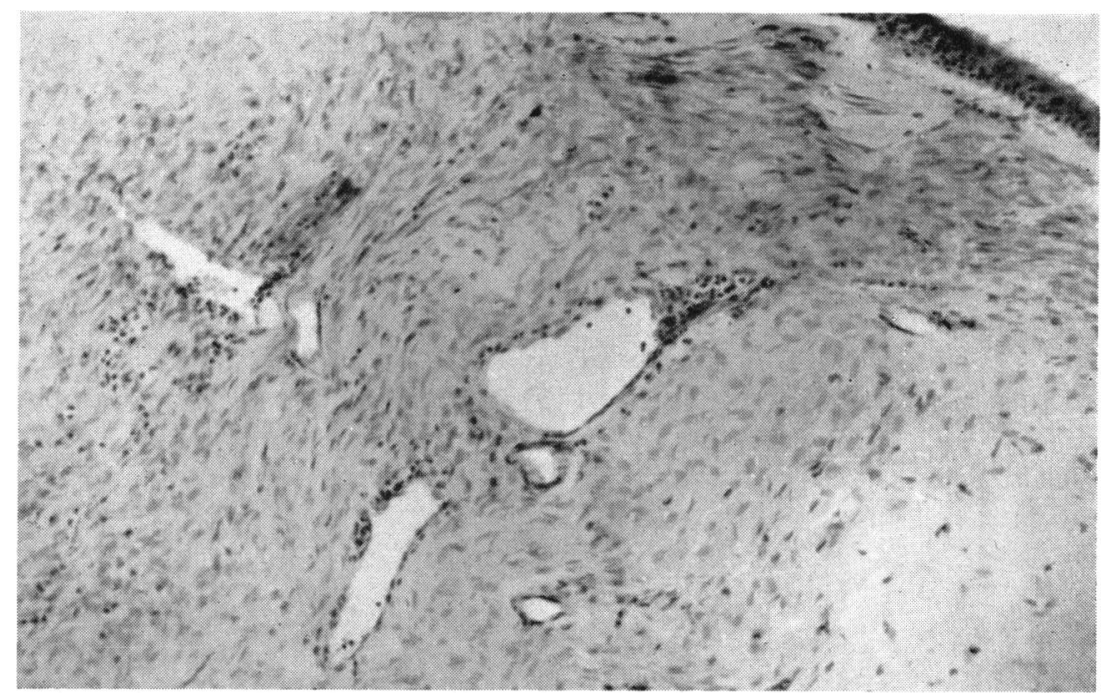

Fig. 1.-Frontal histological section of cornea cauterized with caustic soda. Haematoxylin and eosin. $\times 100$. This section is situated at the apex of the cornea; the larger vessels reach it.

The vessels were chiefly localized in the anterior parenchymal layers (Fig. 2, overleaf).

We also attempted to provoke corneal vascularization by other techniques, but without success. Painting with silver nitrate causes tattooing of the cornea. Intracorneal injection of therebentine provokes a pannus which remains localized to the zone of injection. The injection of alloxan (Langham, 1952) yielded inconstant results.

The rabbits were divided into six groups of eleven to seventeen animals each. The two corneae were cauterized and, to prevent any complications caused by infection, chloramphenicol ointment ( 1 per cent.) was applied to the eyes twice daily. The drugs under test were instilled twice daily into the right eye only, the left eye being used as control. Three * We gratefully acknowledge the help extended by Miss Watillon, M.D., Chief Assistant in the University of Liége, who photo-
graphed the histological sections presented in this paper. 


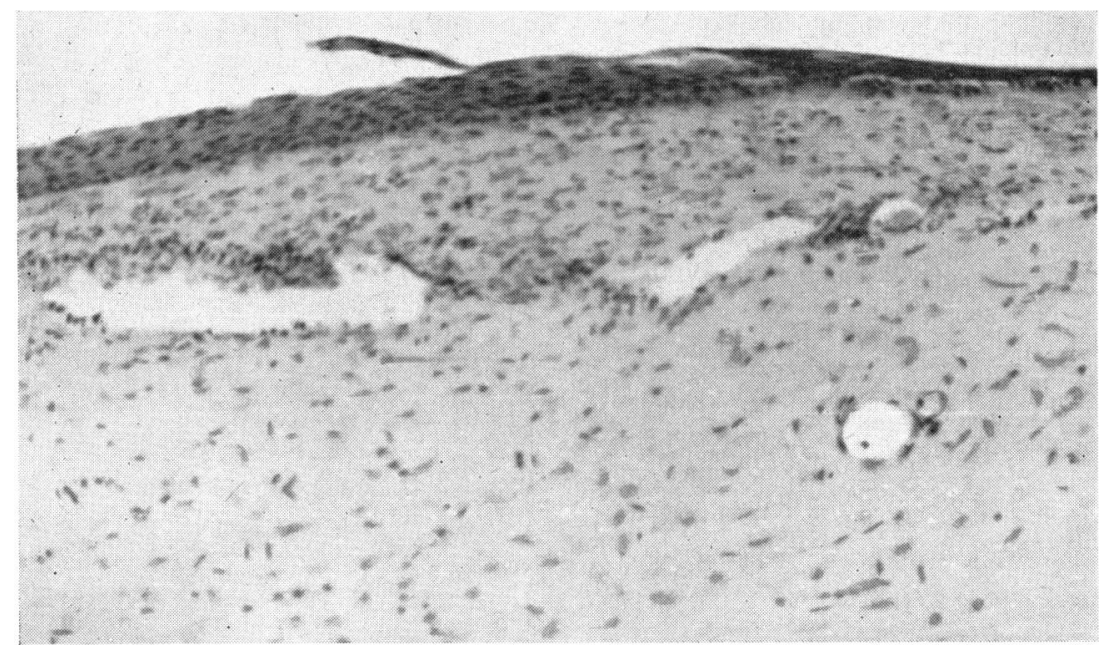

FIG. 2.-Sagittal histological section of cornea cauterized with caustic soda. Haematoxylin and eosin. $\times 100$. The vessels are situated exclusively in the anterior layers of the parenchyma.

groups were treated from the day of cauterization, and the other three groups after an interval of 8 days.

Groups 1 and 4 received the Thiotepa collyrium, Groups 2 and 5 were given the Triamcinolone ointment, and Groups 3 and 6 received both drugs.

The degree of invasion of corneal vessels from the limbus was measured in four segments (nasal, superior, temporal, and inferior) and the arithmetic mean of the measurements was calculated.

In each animal the experiment was considered to be complete when the vascularization reached the centre of one of the corneae.

\section{Results}

Group 1 (Fig. 3, opposite).-The mean encroachment of the vessels in corneae treated with Thiotepa from the moment of cauterization did not exceed $1 \mathrm{~mm}$. The histological sections confirm the macroscopic observation (Fig. 4, opposite).

Group 2 (Fig. 5, opposite).-Triamcinolone given immediately had no effect on vascularization in the cauterized corneae. The macroscopic and microscopic appearances of the corneae treated with this drug did not differ from those of untreated corneae.

Group 3 (Fig. 6, opposite).-The mean vascular growth in corneae treated immediately with a combination of Thictepa and Triamcinolone did not exceed $1 \mathrm{~mm}$. The macroscopic and histological features of these corneae were practically identical with those in eyes treated with Thiotepa only (Group 1).

Group 4 (Fig. 7, overleaf).-The mean encroachment of the vessels in corneae treated with Thiotepa 8 days after cauterization did not exceed $1.7 \mathrm{~mm}$. 


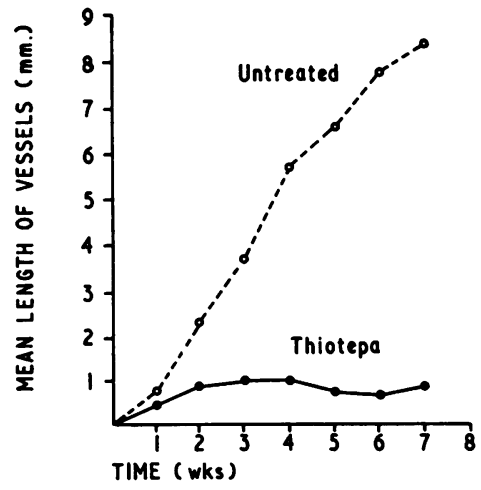

Fig. 3.-Comparison of vascular progression in cauterized corneae treated immediately with Thiotepa and untreated, showing distinct inhibitory effect of Thiotepa.

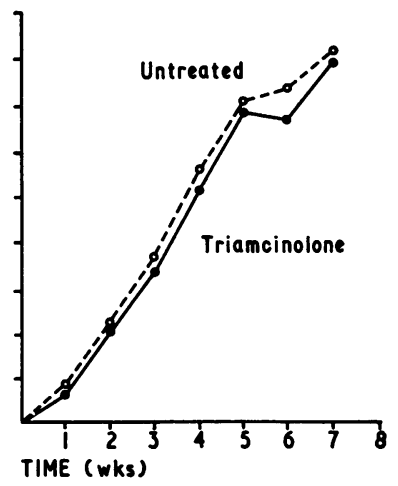

Fig. 5.-Comparison of vascular progression in cauterized corneae treated immediately with Triamcinolone and untreated. Triamcinolone has no inhibitory effect.

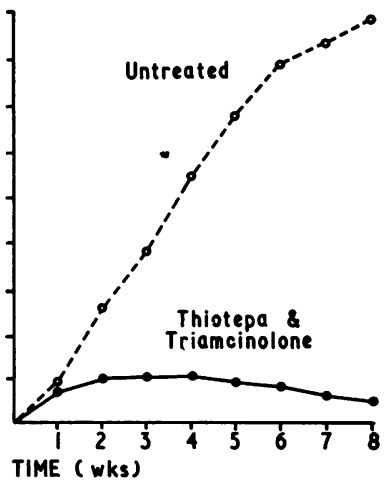

FIG. 6.-Comparison of vascular progression in cauterized corneae treated immediately with a combination of Thiotepa and Triamcinolone and untreated, showing distinct inhibitory effect of the two drugs combined.

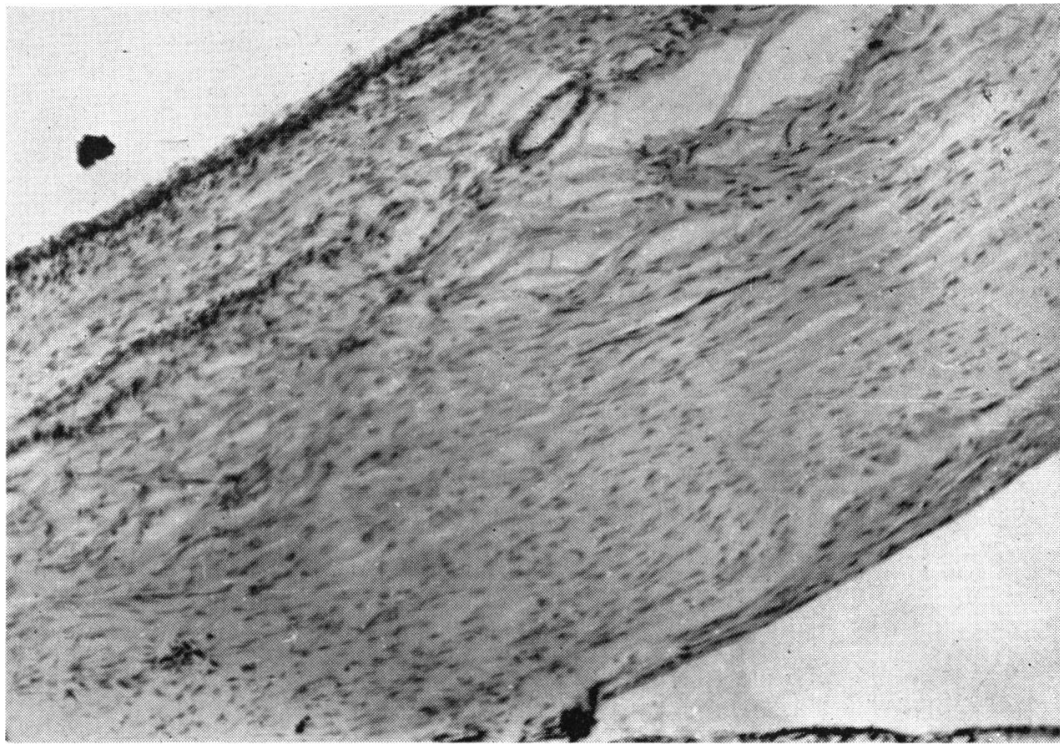

FIG. 4.-Sagittal histological section of cornea cauterized with caustic soda and treated with Thiotepa. Haematoxylin and eosin. $\times 100$. At the top is the section through a vessel localized in the anterior parenchymal layers at the level of the irido-corneal angle, visible at the bottom of the photograph. No vessels are encountered in the more central corneal regions.

Group 5 (Fig. 8, overleaf).-As in Group 2, Triamcinolone given 8 days after cauterization had no inhibitory effect on the vascular growth into the corneae. 
Group 6 (Fig. 9).-The mean encroachment of the vessels in corneae treated with a combination of Thiotepa and Triamcinolone 8 days after cauterization did not exceed $0.85 \mathrm{~mm}$.

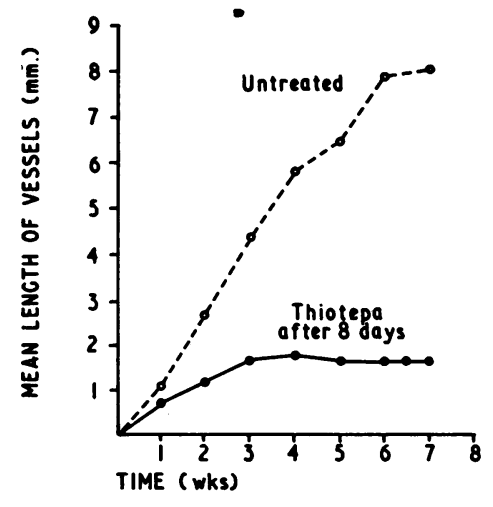

FIG. 7.-Comparison of vascular progression in cauterized corneae treated with Thiotepa after an 8-day interval and untreated, showing the inhibitory effect of Thiotepa.

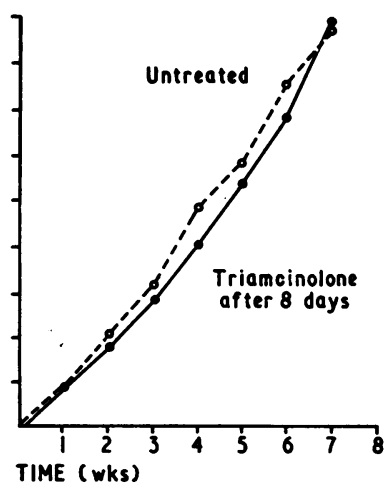

FIG. 8.-Comparison of vascular progression in cauterized corneae treated with Triamcinolone after an 8-day interval and untreated. There is no significant difference.

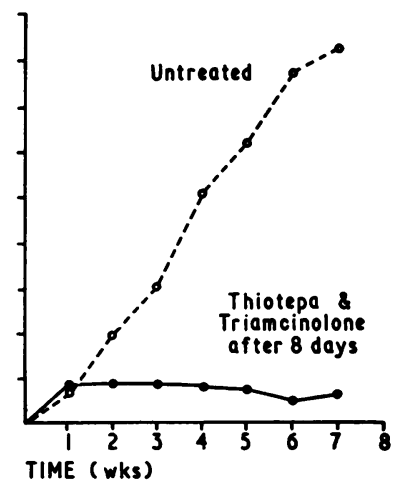

Fig. 9.-Comparison of vascular progression in cauterized corneae treated with a combination of Thiotepa and Triamcinolone after an 8-day interval and untreated. The inhibitory effect of the combination appears to exceed that of Thiotepa alone.

The effect of Thiotepa on the one hand (and the inefficacy of Triamcinolone only on the other) is so pronounced as to obviate the necessity of statistical elaboration. The only point which merits verification is the question whether the combination of Thiotepa with Triamcinolone is more effective than Thiotepa alone.

When treatment was started immediately after cauterization, there was no difference (see Figs 3 and 6), but when treatment was not started until 8 days after cauterization Thiotepa with Triamcinolone seemed to be more effective than Thiotepa alone (Figs 7 and 9). Statistical calculation shows, however, that the difference is significant only for the values obtained in the course of the 4th week.

$$
\begin{aligned}
& \text { Group 4: } n=10 ; m=1.72 \mathrm{~mm} . ; s=1.20 \mathrm{~mm} \text {; } \\
& \text { Group 6: } n=11 ; m=0.77 \mathrm{~mm} \text {.; } s=0.54 \mathrm{~mm} \text {. } \\
& t=2.304 ; 5 \%>\mathrm{P}>2 \% .
\end{aligned}
$$

We observed moreover, that none of the 75 untreated eyes showed any corneal ulceration developing into a descemetocoele and perforation, a complication seen in eight of the treated eyes (four of the 28 eyes treated with Thiotepa alone, two of the 23 treated with Triamcinolone alone, and two of the 24 treated with a combination of the two drugs).

\section{Comment}

Our results confirm those of Langham (1960) and Meacham (1962). Thiotepa, administered as eye-drops retains the antimitotic characteristics which it has when administered by the general route, inhibiting corneal vascularization by blocking the 
multiplication of capillary endothelial cells. But this antimitotic effect also acts upon regeneration of corneal cells, as shown by the relatively large percentage of descemetocoeles among the eyes treated with Thiotepa. Meacham, however, saw no corneal or conjunctival changes in human subjects treated by instillation of a 1/2000 Thiotepa collyrium in Ringer's solution.

In the experimental conditions described, we saw no inhibitory effect of Triamcinolone on the corneal vascularization, though such reaction has been ascribed to corticosteroids by numerous authors (Duke-Elder and Ashton, 1951; Offret, 1952; Paufique and Rougier, 1957; Alberth, 1961b).

Investigators who have approached this problem experimentally have apparently reached contradictory conclusions.

The corneal vascularization provoked by the injection of alloxan into the chamber (Ashton, Cook, and Langham, 1951) or by heat cauterization (Lister and Greaves, 1951 ; Michaelson, 1952) is unmistakably inhibited by cortisone, whether administered in eye-drops or by subconjunctival injection. Wybar and Campbell (1952) also saw an effect of cortisone in rabbits but were unable to reproduce this in guinea-pigs. Leopold, Purnell, Cannon, Steinmetz, and McDonald (1951), like ourselves, provoked corneal vascularization by cauterizing with caustic soda, and found cortisone to be incapable of inhibiting corneal vascularization.

In view of these contradictions, Langham (1952) reconsidered the problem by studying corneal vascularization as a function of one of its precipitating factors, viz: corneal oedema. He concluded that cortisone did not directly inhibit the proliferation of the capillary endothelium but acted by reducing the corneal oedema. The corticosteroids, therefore, arrest the progression of vascularization only when the lesion causing its appearance is relatively mild and they then act only via the corneal oedema which is so produced.

If the corneal changes are severe enough to provoke necrotic lesions, it is probably the substances released by the necrotic foci that cause the corneal vascularization, and in such cases corticosteroids are incapable of preventing further vascularization.

\section{Conclusions}

Thiotepa instilled as drops inhibits the progression of vascularization in the pathological cornea by acting directly upon the multiplication of capillary endothelial cells.

In the experimental conditions described, Triamcinolone had no inhibitory effect on corneal vascularization; it is probable, however, that, by its effect on corneal oedema, Triamcinolone favours the Thiotepa effect and thus contributes to the better results which are observed when the two drugs are used in combination.

The action of Thiotepa and that of Triamcinolone seems to delay or even to curb the process of corneal cicatrization.

\section{REFERENCES}

Alberth, B. (1961a). “Keratoplastik”. Enke, Stuttgart. (1961b). v. Graefes Arch. Ophthal., 163, 562.

ANGIUS, T. (1954). Rass. ital. Ottal., 23, 466.

Ashton, N., CoOK, C., and LANGHAM, M. (1951). Brit. J. Ophthal., 35, 718.

Duke-Elder, S., and Ashton, N. (1951). Ibid., 35, 695. 
Guillaumat, L., Paufique, L., Saint-Martin, R. de, Schiff-Wertheimer, S., and Sourdille, J.-P. (1961). "Traitement chirugical des affections oculaires", vol. 2, p. 16. Doin, Paris.

Hallerman, W. (1961). Klin. Mbl. Augenheilk., 138, 769.

ILIFF, C. E. (1946). Trans. Amer. Acad. Ophthal. Otolaryng., 51, 36. (1947). Arch. Ophthal. (Chicago), 38, 415.

LANGHAM, M. (1952). Trans. ophthal. Soc. U.K., 72, 253. (1960). Amer. J. Ophthal., 49, 1111.

Leopold, I. H., Purnell, J. E., Cannon, E. J., Steinmetz, C. G., and McDonald, P. R. (1951). Ibid., 34,361 .

Lister, A., and Greaves, D. P. (1951). Brit. J. Ophthal., 35, 725.

MeACHAM, C. T. (1962). Amer. J. Ophthal., 54, 751.

Michaelson, I. C. (1952). Arch. Ophthal. (Chicago), 47, 459; 48, 144.

OFFRET, G. (1952). Année thérapeutique Ophtal., 3, 211. and Chauvet, P. (1950). Arch. Ophtal. (Paris), n.s. 10, 344; $480 ; 593$.

Paufique, L., and Rougier, J. (1957). In "Thérapeutique médicale oculaire", ed. J. Sédan, J. Malbrán, G. E. Jayle, J. François, and G. Calamandrei, vol. 1, p. 833. Masson, Paris.

Wybar, K. C., and Campbell, F. W. (1952). Trans. ophthal. Soc. U.K., 72, 105. 